(2) Open Access Full Text Article

REVIEW

\title{
Long-term efficacy and safety of iloperidone: an update
}

This article was published in the following Dove Press journal:

Neuropsychiatric Disease and Treatment

26 February 2014

Number of times this article has been viewed

\section{Jeffrey T Rado}

Philip G Janicak

Rush University Medical Center, Chicago, IL, USA
Correspondence: Jeffrey T Rado Rush University Medical Center, 2I 50 W Harrison St, Chicago,

IL 606I2, USA

Tel +I 3129427287

Email jeffrey_rado@rush.edu
Abstract: Schizophrenia is a devastating neuropsychiatric disease with a worldwide prevalence of approximately $0.5 \%-1 \%$. Since many patients do not achieve adequate symptom relief from available agents, alternate pharmacotherapeutic approaches are needed. In this context, iloperidone was recently approved by the US Food and Drug Administration for the treatment of schizophrenia. This paper first reviews its pharmacodynamic and pharmacokinetic profiles, emphasizing their clinical relevance. Next, it summarizes the literature on its acute and maintenance efficacy, safety, and tolerability. It then considers pharmacogenetic data which may help to predict response and risk of cardiac arrhythmias with this agent. Finally, it critically positions iloperidone relative to other first- and second-generation antipsychotics.

Keywords: schizophrenia, iloperidone, antipsychotic

\section{Introduction}

Symptoms of schizophrenia typically include hallucinations and delusions (positive symptoms), asociality, alogia, anergia, anhedonia, and flat affect (negative or deficit symptoms), mood and anxiety symptoms, and cognitive dysfunction. ${ }^{1}$ Relapses are frequent and substantial impairment in academic, social, and vocational activities are common. As a result, many patients never return to premorbid functioning. Psychosocial rehabilitation and pharmacotherapy are standard treatment approaches. Long-term antipsychotic therapy is usually required to control symptoms and prevent relapse or recurrence. While non-clozapine, second-generation antipsychotics (SGAs) have a relatively lower risk of extrapyramidal symptoms (EPS) and possibly improved efficacy for mood symptoms, their overall efficacy appears similar to first-generation antipsychotics. ${ }^{2}$ Iloperidone is a recently approved SGA. While its efficacy seems similar to other antipsychotics; its pharmacodynamic, pharmacokinetic, and pharmacogenetic profiles may help differentiate it from other agents in this class.

\section{Pharmacodynamics}

Iloperidone administered to rats leads to increases in medial prefrontal cortical dopamine and acetylcholine release and a relatively smaller increase in dopamine release in the nucleus accumbens. ${ }^{3}$ Its clinical benefit for psychosis may result from antagonism of both dopamine and serotonin receptors. Its binding profile resembles that of other SGAs, with a high $5 \mathrm{HT}_{2 \mathrm{~A}} / \mathrm{D}_{2}$ ratio and varying affinities (all as an antagonist) for other receptors, including: ${ }^{4,5}$ 
1. High affinity for:

- Dopamine $\mathrm{D}_{3}$ receptors

- Serotonin $5 \mathrm{HT}_{2 \mathrm{a}}$ receptors

- Norepinephrine $\alpha_{1}$ adrenergic receptors

2. Intermediate to high affinity for:

- Norepinephrine $\alpha_{2 c}$ receptors

3. Intermediate affinity for:

- Dopamine $\mathrm{D}_{2 \mathrm{a}}$ and $\mathrm{D}_{4}$ receptors

- $5 \mathrm{HT}_{1 \mathrm{~A}}, 5 \mathrm{HT}_{2 \mathrm{C}}$, and $5 \mathrm{HT}_{6}$ receptors

4. Low affinity for:

- Norepinephrine $\alpha_{2 \mathrm{a}}, \alpha_{2 \mathrm{~b},}, \beta_{1}, \beta_{2}$, receptors

- Histamine $\mathrm{H}_{1}$ receptors

- Dopamine $\mathrm{D}_{1}$ and $\mathrm{D}_{5}$ receptors

5. Negligible affinity for:

- Muscarinic $\mu_{1}-\mu_{5}$ receptors

- Dopamine and norepinephrine reuptake transporters.

There is an increased risk for orthostatic hypotension resulting from $\alpha_{1}$ adrenergic antagonism, while minimal muscarinic antagonism reduces the risk of peripheral and central anticholinergic adverse effects. ${ }^{5}$

\section{Pharmacokinetics}

Peak plasma concentration $\left(\mathrm{C}_{\max }\right)$ of iloperidone is reached 2-4 hours after oral administration. ${ }^{6}$ Its elimination half-life $\left(\mathrm{t}_{1 / 2}\right)$ ranges from 18 hours for extensive cytochrome P450 2D6 (CYP2D6) metabolizers to 33 hours for poor metabolizers. The bioavailability of iloperidone is $96 \%{ }^{6}$ It is metabolized in the liver by the CYP3A4 and CYP2D6 enzyme pathways and circulates $95 \%$ bound to serum proteins. ${ }^{6}$ Individual genetic variations in CYP2D6 or CYP3A4 may affect a patient's ability to metabolize iloperidone. Co-administration of potent CYP2D6 or CYP3A4 inhibitors may warrant a reduction in the dose of iloperidone. It has two major metabolites: P88-8991 and P95-12113. P88-8991 shares similar receptor binding affinities with the parent compound. P95-12113 exhibits a lower affinity for the $5 \mathrm{HT}_{2 \mathrm{a}}$ receptor, does not cross the blood-brain barrier, and therefore does not contribute to the clinical effects of iloperidone. ${ }^{7}$ P95-12113 binds to receptors with a significantly lower affinity than iloperidone; therefore, no additional side effects are thought to arise from this peripheral metabolite.

\section{Clinical efficacy for acute schizophrenia \\ Phase III trials}

The acute efficacy of iloperidone for schizophrenia was studied in four Phase III trials. Potkin et al reported the results from three 6-week, double-blind, active- and placebo-controlled studies in men and women (aged 18-65 years) with schizophrenia or schizoaffective disorder. ${ }^{8}$ At baseline, subjects scored $\geq 60$ on the Positive and Negative Syndrome Scale (PANSS). ${ }^{9}$ Each study began with an initial single-blind, 3-day, placebo run-in phase. Following a 7-day titration period, patients received 5 weeks of fixed-dose treatment. Those who received at least one dose of medication and one post-baseline PANSS assessment were included in an intent-to-treat analysis.

In the first study, 621 patients were randomized in a 1:1:1:1:1 fashion to iloperidone $(4,8$, or $12 \mathrm{mg}$ /day), haloperidol (15 mg/day), or placebo. The primary outcome measure was change from baseline on the total PANSS (PANSS-T) score. Completion rates ranged from placebo (31\%), iloperidone $4 \mathrm{mg} /$ day (43\%), iloperidone $8 \mathrm{mg}$ /day (36\%), and iloperidone $12 \mathrm{mg} /$ day (42\%). Compared with placebo, significant improvement from baseline in the PANSS-T scores occurred in the iloperidone $12 \mathrm{mg}$ /day group $(-9.9$ versus -4.6 points; $P<0.047)$ and haloperidol group $(-13.9$ versus -4.6 points, $P<0.001)$. Scores on the Brief Psychiatric Rating Scale (BPRS) were also significantly improved in the $12 \mathrm{mg}$ group compared with placebo $(P<0.042)$.

The second study involved 616 patients randomized in a 1:1:1:1 fashion to iloperidone ( $4-8 \mathrm{mg} /$ day), iloperidone (10-16 mg/day), risperidone (4-8 mg/day), or placebo. The primary outcome measure was change score from baseline on the total BPRS score. Completion rates were $56 \%$ for the iloperidone group ( $48 \%$ for the $4-8 \mathrm{mg}$ /day group, $56 \%$ for the $10-16 \mathrm{mg} /$ day group), $58 \%$ for the risperidone group, and $40 \%$ for placebo. Significant improvement from baseline on the total BPRS score was seen in the iloperidone $4-8 \mathrm{mg} /$ day group ( $P<0.012$ versus placebo), $10-16 \mathrm{mg} /$ day group $(P<0.001$ versus placebo) group, and the risperidone group $(P<0.001$ versus placebo). A statistically significant improvement on the PANSS positive symptom subscale (PANSS-P) was also observed in the iloperidone $4-8 \mathrm{mg}$ /day group $(P<0.020)$. Similar findings were also seen for the general psychopathology subscale $(P<0.017)$ and the Clinical Global Impression - Severity scale (CGI-S; $P<0.003)$. Compared with placebo, the $10-16 \mathrm{mg}$ /day group also demonstrated significantly greater improvement on PANSS-T $(P<0.002)$, PANSS-P $(P<0.002)$, PANSS negative symptoms subscale (PANSS-N; $P<0.003)$, and CGI-S $(P<0.006)$.

A third study randomized 706 patients in a 1:1:1:1 fashion to iloperidone (12-16 mg/day), iloperidone (20-24 mg/day), risperidone (6-8 mg/day), or placebo. Titration of iloperidone occurred over 7 days. Of note, risperidone was titrated up to 
$6 \mathrm{mg} /$ day after only 2 days. The primary outcome measure was change score from baseline on the total BPRS. Compared with placebo, the iloperidone $20-24 \mathrm{mg} /$ day $(P<0.010)$ and risperidone groups $(P<0.001)$ demonstrated statistically significant improvement from baseline. The iloperidone 20-24 mg/day group also resulted in significant reductions in PANSS-T $(P<0.005)$, PANSS-P $(P<0.008)$, PANSS-N $(P<0.023)$, and CGI-S $(P<0.037)$ scores compared with placebo. Lower doses of iloperidone (12-16 mg/day group) did not result in a significant improvement in the BPRS, although they did lead to significant improvement on the CGI-S $(P<0.028)$.

While efficacy relative to the active comparative agent was not the primary objective of these studies, initial analyses indicated that iloperidone may be less effective than risperidone. In these studies, iloperidone was titrated over 1 week, while risperidone was titrated more quickly. Consequently, steady state plasma concentrations of risperidone may have occurred earlier than iloperidone. As a result, a combined analysis of the three studies was conducted in all subjects who completed $\geq 2$ weeks of double-blind treatment $(n=1,553)$ to account for the impact of early discontinuations (ie, before day 7 , the time required to reach steady state concentration). ${ }^{12}$ This analysis demonstrated that iloperidone was associated with statistically significant improvement compared with placebo and similar improvement for each dose of iloperidone relative to the active comparator.

In the final study, Cutler et al randomized 593 adult men and women with schizophrenia in a 2:1:1 fashion under double-blind conditions to iloperidone ( $24 \mathrm{mg} /$ day), ziprasidone $(160 \mathrm{mg} /$ day $)$, or placebo. ${ }^{10}$ Subjects scored $\geq 70$ on the PANSS-T at baseline and had a score of at least four on two of the PANSS-P items (ie, delusions, conceptual disorganization, hallucinations, or suspiciousness/persecution). Ziprasidone was chosen as the active comparator because its adverse effect profile and titration schedule are similar to iloperidone. This was important because it was postulated that investigators in the earlier studies might assume patients not reporting adverse effects or experiencing a clinical response were on placebo, when they were actually on iloperidone but the titration was not yet complete. As a result, these patients may have prematurely left the study before having adequate time to experience a clinical response. ${ }^{11}$ The hope was that this would be avoided since the titration of ziprasidone matched that of iloperidone.

Screening occurred over the first 3-14 days, followed by a 1 week titration and then 3 weeks of fixed-dose treatment. Ziprasidone was titrated as follows: $20 \mathrm{mg}$ twice daily (days 1-2); $40 \mathrm{mg}$ twice daily (days 3-4); $60 \mathrm{mg}$ twice daily (days 5-6); and then $80 \mathrm{mg}$ twice daily (day 7 onward). Iloperidone was dosed twice daily $(1,2,4,6,8,10$, and $12 \mathrm{mg}$ ) over days $1-7$. All patients who received at least one dose of medication and at least one post-baseline PANSS assessment were included in the intention-to-treat analysis. The primary outcome measure was PANSS-T change score. Improvement from baseline was observed in patients treated with iloperidone ( -12.0 points, $P<0.01$ versus placebo), as well as ziprasidone ( -12.3 points, $P<0.05$ versus placebo). Compared with placebo, the iloperidone- and ziprasidonetreated groups also demonstrated significant improvement on the BPRS $(P<0.05)$, PANSS-P $(P<0.001$ and $P<0.01$, respectively), PANSS-N $(P<0.05)$, and CGI-S $(P<0.01$ and $P<0.05$, respectively). Greater efficacy was also seen for the active comparator group versus placebo, supporting the validity of the study results.

Finally, Citrome et al conducted a post hoc analysis of all four, short-term acute schizophrenia trials $(n=2,401) .{ }^{12}$ Using an intention-to-treat analysis, iloperidone (10-16 mg/day and 20-24 mg/day) was associated with significantly improved scores on the BPRS $(P<0.05)$, PANSS-T $(P<0.05)$, PANSS-P $(P<0.05)$, and PANSS-N $(P<0.05)$ compared with placebo.

\section{Long-term efficacy in schizophrenia}

Kane et al reported on the long-term efficacy data from three iloperidone trials. ${ }^{13}$ Patients who obtained $\geq 20 \%$ reduction in their PANSS-T score after completing an initial 6-week acute trial could enter an extended maintenance phase. Subjects $(n=1,644)$ were randomized in a 3:1 ratio to either iloperidone (4-16 mg/day) or haloperidol (5-20 mg/day). The primary outcome measure was time-to-relapse (defined as $\mathrm{a} \geq 25 \%$ increase in PANSS-T score with at least a 10-point increase), discontinuation due to lack of efficacy, hospitalization for aggravated psychosis, or a two-point decrease on the CGI - Change scale after week 6. Of these, 473/1,326 (36\%) completers qualified for the extension trial, during which discontinuation rates were similar in the iloperidone and haloperidol groups (ie, $36.4 \%$ in each group). Relapse rates were also similar (ie, $43.5 \%$ in the iloperidone group and $41.2 \%$ in the haloperidol group). The authors concluded that the two drugs demonstrated equivalency with regard to the primary and secondary outcome measures.

Cutler et al reported the results from a more recent, long-term maintenance trial. ${ }^{14}$ Patients enrolled in the doubleblind, placebo- and ziprasidone-controlled, acute efficacy trial who obtained a CGI - Change score of four (indicating 
improvement) at the end of the double-blind phase were allowed to continue into a 25-week, open-label extension trial. ${ }^{15}$ All patients received iloperidone (12 mg twice daily), which could be reduced to $6 \mathrm{mg}$ twice daily at the investigator's discretion. At 25 weeks (ie, endpoint), there was no significant decrease in baseline PANSS-T scores. Using a last observation carried forward analysis, mean changes in the CGI from the beginning of the double-blind phase to endpoint were $-1.3( \pm 1.3)$ for those previously on iloperidone, -1.3 $( \pm 1.2)$ for those switched to iloperidone from ziprasidone, and $-1.2( \pm 1.2)$ for those switched to iloperidone from placebo. The overall discontinuation rate was $58.4 \%$, higher than the discontinuation rate in the other long-term iloperidone trials (ie, 36.4\%). ${ }^{8}$ The CGI - Improvement scale was used to measure clinical change from the end of the double-blind phase with $56.3 \%$ rated as very much improved, $22.8 \%$ as minimally improved, $12.6 \%$ as no change, and $8.4 \%$ (14 patients) experiencing a worsening of their scores.

\section{Safety and tolerability}

A pooled analysis of safety outcomes from the first three acute trials was conducted by Weiden et al. ${ }^{15}$ All patients who received at least one dose of study medication were included in the analysis $(n=1,912)$. In all groups, the most common treatment-emergent adverse events were dry mouth, somnolence, dizziness, and dyspepsia. EPS were the most common treatment-emergent adverse events in the haloperidol- and risperidone-treated groups. Serious adverse events were experienced by ten patients $(<1 \%)$ who received iloperidone (10-16 mg/day) versus $11 \%$ in the haloperidol group and there were no deaths. Discontinuation due to adverse events occurred in 3.9\%-5.6\% of the iloperidone group (most common reason was dizziness), 7.6\% of the haloperidol group (most common reason was tremor), 6.2\% of the risperidone group (most common reason was EPS), and $4.8 \%$ of the placebo group. Baseline to endpoint assessment of EPS and akathisia (as measured by the EPS Rating Scale) improved in patients treated with iloperidone, compared with no change in those receiving risperidone and worsening in those on haloperidol. The improvement in EPS observed with iloperidone may be due in part to discontinuation of previous antipsychotics.

Baseline to endpoint QT prolongation was dose-related (ie, 2.9 milliseconds in the 4-8 mg group, 3.9 milliseconds in the 10-16 mg group, and 9.1 milliseconds in the $20-24 \mathrm{mg}$ group). By contrast, the risperidone group experienced a mean 0.6 millisecond increase while the haloperidol group increased 5 milliseconds. Initial orthostatic hypotension was experienced by $19.5 \%$ of those treated with iloperidone, but did not persist beyond the first week of treatment.

Dose-related increases in plasma glucose were 7.2, 9.0 , and $16.2 \mathrm{mg} / \mathrm{dL}$ with iloperidone 4-8, 10-16, and 20-24 mg/day, respectively. By comparison, mean plasma glucose increases in the haloperidol and risperidone groups were $10.8 \mathrm{mg} / \mathrm{dL}$ and $3.6 \mathrm{mg} / \mathrm{dL}$, respectively. Using a last observation carried forward analysis, clinically significant weight gain (ie, $\geq 7 \%$ from baseline) occurred in $12.3 \%$ of iloperidone subjects, $11.9 \%$ of risperidone subjects, and $5.1 \%$ of haloperidol subjects. The highest rate (ie, $15.2 \%$ ) occurred in the iloperidone 20-24 mg/day group. Average weight gain among the iloperidone-treated subjects was 1.5 , 2.1 , and $1.7 \mathrm{~kg}$ in the 4-8, 10-16, and 20-24 mg/day groups, respectively. While no significant weight gain occurred with haloperidol or placebo, those on risperidone experienced a mean weight gain of $1.5 \mathrm{~kg}$.

Sedation, weight gain, dizziness, tachycardia, dry mouth, nasal congestion, and orthostatic hypotension were the most common adverse events with iloperidone noted in the fourth trial. ${ }^{10}$ Of the nine subjects $(2 \%)$ who developed serious adverse events, three (one on iloperidone and two on ziprasidone) had worsening of psychosis and two subjects (both on placebo) experienced seizures. No deaths were reported. Iloperidone was discontinued in 5\% of patients due to adverse events, with worsening of psychosis being the most common reason. Meanwhile, $8 \%$ of both the ziprasidone and placebo groups discontinued due to adverse events, with worsening of psychosis being the most common reason. Iloperidone, ziprasidone, and placebo produced weight gains of $2.8,1.1$, and $0.5 \mathrm{~kg}$, respectively. Clinically significant weight gain was experienced by $3 \%$ of the placebo group, $7 \%$ of the ziprasidone group, and $21 \%$ of the iloperidone group. Mean changes in total cholesterol levels were $8.1,4.1$, and $-0.5 \mathrm{mg} / \mathrm{dL}$ for the iloperidone, ziprasidone, and placebo groups, respectively. Baseline to day 28 mean increase in QT duration was not significantly different between the iloperidone (ie, 7.2 milliseconds) and ziprasidone (ie, 6.1 milliseconds) groups.

Compared with placebo, patients on iloperidone demonstrated improvement on EPS ratings for dyskinesia, akathisia, dystonia, acute torsion dystonia, and trunk/limb dyskinesia. Similar numbers of patients on iloperidone and placebo demonstrated improvement or lack of change on the Barnes Akathisia Scale.

In the long-term maintenance trials, the most common adverse events associated with iloperidone were insomnia (18.1\%), anxiety (10.8\%), and worsening of 
schizophrenia (8.9\%). ${ }^{13}$ EPS scores worsened overall in the haloperidol group while they improved with iloperidone.

The primary objective of the second, long-term extension trial was safety and tolerability. ${ }^{14}$ As previously described, patients from the 4-week, double-blind, placebo- and ziprasidone-controlled acute trial were switched to open-label iloperidone for 25 weeks. Safety assessments included adverse events, concomitant medication use, changes in vital signs, metabolic parameters, electrocardiogram and other laboratory values, as well as standard assessments of EPS. The most common treatment-emergent adverse events were headache (13.9\%), weight gain $(9.2 \%)$, dizziness $(6.9 \%)$, nausea $(6.4 \%)$, and insomnia (5.2\%). The only dose-related adverse events were headache and weight gain. While serious adverse events were experienced by 15 patients and included one death, none were judged to be related to the study medication.

Clinically significant weight gain was observed in $47.7 \%$ of those previously on iloperidone, $34.8 \%$ of those switched from ziprasidone, and $19.5 \%$ of those switched from placebo. No significant increases were seen in glucose, lipids, and prolactin. Orthostatic response (systolic blood pressure decrease $>30 \mathrm{mmHg}$ ) occurred in $9.3 \%$ of those previously on iloperidone, $8.7 \%$ of those switched from ziprasidone, and $14.6 \%$ of those switched from placebo. Mean change in QT interval was $0.7( \pm 0.21) \mathrm{msec}$ in those previously on iloperidone, $3.8( \pm 19.4)$ in those switched from ziprasidone, and 6.3 $( \pm 22.1) \mathrm{msec}$ in those switched from placebo. Scores on the Barnes Akathisia Scale, CGI-S, and akathisia subscales of the EPS Rating Scale demonstrated improvement or no change for all groups. Similarly, no significant change in overall EPS was noted.

Case reports also describe postmarketing adverse events. A 35-year-old female with schizophrenia experienced galactorrhea 3 months after starting iloperidone ( $8 \mathrm{mg} /$ day) ${ }^{16}$ Freeman reported two cases of retrograde ejaculation in two young males (aged 21 and 24 years) with schizophrenia after taking iloperidone ( $8 \mathrm{mg}$ twice daily) for 2 or 3 weeks. ${ }^{17}$ Finally, a 29 -year-old male taking iloperidone (16 mg/day) developed palpitations and was diagnosed with premature ventricular contractions. ${ }^{19}$ Symptoms in all these cases resolved after stopping iloperidone and switching to alternate therapies.

\section{Genetic predictors of response and QT prolongation}

Patients with schizophrenia have a highly variable and often unpredictable response to antipsychotic medication. As reported in the Clinical Antipsychotic Trials of
Intervention Effectiveness (CATIE) trial, 74\% of patients discontinued their original antipsychotic agent within 18 months of its initiation. ${ }^{20}$ Genetics are an important determinant of response, as well as for the occurrence of adverse effects. Since treatment response involves many factors, the usefulness of predictive genetic markers continues to remain under investigation.

Lavedan et al conducted a genome-wide association study of the efficacy response to iloperidone in a Phase III trial. ${ }^{21}$ Based on change in the PANSS-T score after 4 weeks of iloperidone treatment, a genetic association was assessed for 334,563 single nucleotide polymorphisms (SNPs). Six SNPs appeared to predict response to this antipsychotic. They included NPAS3, XKR4, TNR, GRIA4, GFRA2, and NUDT9PI. These six SNPs were previously linked to schizophrenia or related disorders and were then used to predict response in the 4-week, randomized trial comparing iloperidone to placebo with ziprasidone as an active control. Likelihood ratios, predicted probabilities of response, and number needed-to-treat were calculated for patients with schizophrenia. ${ }^{22}$ Of patients with the "optimal" genotype, $75 \%$ experienced $\geq 20 \%$ improvement from their baseline PANSS-T scores compared with only $37 \%$ of those who did not have these genotypes. Further, those with the "optimal" genotype combination also had a more robust response by the end of week 1 . The odds of responding peaked at $\geq 9.5$ for those with all six single-marker genotypes. Of note, this relationship was not observed with ziprasidone.

Volpi et al also reported on a whole genome association study which identified several polymorphisms associated with QT prolongation in patients on iloperidone for 2 weeks. ${ }^{23}$ They included CERKL, SLCO3A1, BRU-NOL4, NRG3, $P A L L D$, and NVBPL. While some of these genes are known to impact cardiac structure and function, none were previously associated with cardiac repolarization or ventricular tachycardia.

The value of such analyses is to better assess the risk/ benefit ratio of a specific drug such as iloperidone. However, more data and independent replication are necessary. For example, Fijal et al recently reported that two SNPs (XKR4 and GR1A4) found to predict response to iloperidone were also associated with response to risperidone. ${ }^{24}$

\section{Conclusion}

Iloperidone is a recently approved antipsychotic which demonstrates acute and longer-term efficacy for schizophrenia. While early trials produced mixed results, the outcomes from acute trials which took into account the 
need for a slower initial dosing titration found this agent to be superior to placebo and similar to other non-clozapine SGAs and haloperidol. Results from four long-term maintenance trials indicate similar rates of discontinuation when compared with haloperidol or ziprasidone.

Dizziness, orthostasis, and somnolence are the most common adverse effects related to iloperidone. Of note, QT prolongation with iloperidone is greater than other recently approved agents (eg, asenapine, lurasidone). Weight gain and prolonged QT duration are both moderate risks. The recommended dose range of $12-24 \mathrm{mg} /$ day is titrated over the first week to minimize orthostatic hypotension. For patients requiring rapid stabilization, the necessity for a slower dose titration and twice daily dosing recommendation diminish the role of this agent for acute management. Its metabolic profile indicates that weight gain and related lipid and glucose parameters may pose an increased risk with higher doses and longer-term exposure, but more data from controlled trials are needed..$^{25}$ The safety and tolerability of iloperidone indicate a profile which may be useful for patients with a proclivity to EPS (eg, akathisia) or anticholinergic-related adverse effects. While the potential use of pharmacogenetics to predict clinical response is exciting, its clinical utility for iloperidone is yet to be established. In addition, there is no data regarding this agent's effectiveness in real world scenarios, its potential role in younger and elderly patients, or safety during pregnancy and nursing. ${ }^{26}$

\section{Disclosure}

Dr Rado and Dr Janicak have received research support from Sunovion, Otsuka, and Janssen Pharmaceuticals. They report no other conflicts of interest in this work.

\section{References}

1. Ivleva ER, Tamminga CA. Psychosis as a defining dimension in schizophrenia. In: Sadock BJ, Sadock VA, Ruiz P, editors. Kaplan and Sadock's Comprehensive Textbook of Psychiatry. 9th ed. Philadelphia, PA: Lippincott Williams and Wilkins; 2009:1594-1596.

2. Rado JT, Janicak PG. Schizophrenia. In: Rakel RE, Bope E, editors. Conn's Current Therapy. 61st ed. Philadelphia, PA: Saunders; 2009: 1128-1131.

3. Ichikawa J, Li Z, Dai J, Meltzer HY. Atypical antipsychotic drugs, quetiapine, iloperidone, and melperidone, preferentially increase dopamine and acetylcholine release in rat medial prefrontal cortex: role of 5-HT $\mathrm{H}_{1 \mathrm{~A}}$ receptor agonism. Brain Res. 2002;956(2):349-357.

4. Kalkman HO, Feuerbach, Lotscher E, Schoeffter P. Functional characterization of the novel antipsychotic iloperidone at human $\mathrm{D}_{2}, \mathrm{D}_{3}, \alpha_{2 \mathrm{C}}$, 5-HT, and 5-HT ${ }_{1 \mathrm{~A}}$ receptors. Life Sci. 2003;73(9):1151-1159.

5. Kalkman HO, Subramanian N, Hoyer D. Extended radioligand binding profile of iloperidone: a broad spectrum dopamine/serotonin/ norepinephrine receptor antagonist for the management of psychotic disorders. Neuropsychopharmacology. 2001;25(6):904-914.

6. Citrome L. Iloperidone: chemistry, pharmacodynamics, pharmacokinetics and metabolism, clinical efficacy, safety and tolerability, regulatory affairs, and an opinion. Expert Opin Drug Metab Toxicol. 2010;6(12):1551-1564.
7. Subramanian N, Kalkman HO. Receptor profile of P88-8991 and P95-12113, metabolites of the novel antipsychotic iloperidone. Prog Neuropsychopharmacol Biol Psychiatry. 2002;26(3):553-560.

8. Potkin SG, Litman RE, Torres R, Wolfgang CD. Efficacy of iloperidone in the treatment of schizophrenia: initial Phase III studies. J Clin Psychopharmacol. 2008;28(2 Suppl 1):S4-S11.

9. Kay SR, Fiszbein A, Opler LA. The positive and negative syndrome scale (PANSS) for schizophrenia. Schizophr Bull. 1987;13(2):261-276.

10. Cutler AJ, Kalali AH, Weiden PJ, Hamilton J, Wolfgang CD. Four-week, double-blind, placebo- and ziprasidone-controlled trial of iloperidone in patients with acute exacerbations of schizophrenia. J Clin Psychopharmacol. 2008;28(2 Suppl 1):S20-S28.

11. Cutler AJ, Bishop JR. An update on the investigational antipsychotic iloperidone: an expert interview with Andrew J. Cutler, MD. Medscape Psychiatry. April 16, 2008. Available from: http://www.medscape.com/ viewarticle/571878. Accessed September 21, 2009.

12. Citrome L, Meng X, Hochfelt M, Stahl S. Efficacy of iloperidone in the short-term treatment of schizophrenia: a post-hoc analysis of pooled patient data from four Phase III, placebo- and active-controlled trials. Hum Psychpharmacol. 2013;27(1):24-32.

13. Kane JM, Lauriello J, Laska E, Di Marino M, Wolfgang CD. Longterm efficacy and safety of iloperidone: results from 3 clinical trials for the treatment of schizophrenia. J Clin Psychopharmacol. 2008;28(2 Suppl 1):S29-S35.

14. Cutler AJ, Kalali AH, Mattingly GW, Kunovac J, Meng X. Long-term safety and tolerability of iloperidone: results from a 25-week, open-label extension trial. CNS Spectr. 2013;18(1):43-54.

15. Weiden PJ, Cutler AJ, Polymeropoulos MH, Wolfgang CD. Safety profile of iloperidone: a pooled analysis of 6-week acute-phase pivotal trials. J Clin Psychopharmacol. 2008;28(2 Suppl 1):S12-S19.

16. Dutta A, Barua S, Dan A, Chakraborty K, Mandal M. Iloperidoneinduced galactorreha in a middle-aged female. Indian J Psychol Med. 2012;34(4):396-398.

17. Freeman SA. Iloperidone-induced retrograde ejaculation. Int Clin Pychopharmacol. 2013;28(3):156.

18. Guanci N, Aggarwal R, Schleifer S. Atypical neuroleptic malignant syndrome associated with iloperidone administration. Psychosomatics. 2012;53(6):603-605.

19. Achalia R, Andrade C. Ventricular premature contractions associated with iloperidone. Indian J Psychiatry. 2013;55(2):195-196.

20. Lieberman JA, Stroup TS, McEvoy JP, et al. Effectiveness of antipsychotic drugs in patients with chronic schizophrenia. $N$ Engl J Med. 2005;353(12):1209-1223.

21. Lavedan C, Licamele L, Volpi S, et al. Association of the NPAS3 gene and five other loci with response to the antipsychotic iloperidone identified in a whole genome association study. Mol Psychiatry. 2009;14(8):804-819.

22. Volpi S, Potkin SG, Malhotra AK, Licamele L, Lavedan C. Applicability of a genetic signature for enhanced iloperidone efficacy in the treatment of schizophrenia. J Clin Psychiatry. 2009;70(6):801-809.

23. Volpi S, Heaton C, Mack K, et al. Whole genome association study identifies polymorphisms associated with QT prolongation during iloperidone treatment of schizophrenia. Mol Psychiatry. 2009;14(11):1024-1031.

24. Fijal BA, Stauffer VL, Kinon BJ, et al. Analysis of gene variants previously associated with iloperidone response in patients with schizophrenia who are treated with risperidone. J Clin Psychiatry. 2012;73(3):367-371.

25. De Hert M, Yu W, Detraux J, Sweers K, van Winkel R, Correll CU. Body weight and metabolic adverse effects of asenapine, iloperidone, lurasidone and paliperidone in the treatment of schizophrenia and bipolar disorder: a systematic review and exploratory meta-analysis. CNS Drugs. 2012;26(9):733-759.

26. Bobo WV. Asenapine, iloperidone and lurasidone: critical appraisal of the most recently approved pharmacotherapies for schizophrenia in adults. Expert Rev Clin Pharmacol. 2013;6(1):61-91. 
Neuropsychiatric Disease and Treatment

Dovepress

\section{Publish your work in this journal}

Neuropsychiatric Disease and Treatment is an international, peerreviewed journal of clinical therapeutics and pharmacology focusing on concise rapid reporting of clinical or pre-clinical studies on a range of neuropsychiatric and neurological disorders. This journa is indexed on PubMed Central, the 'PsycINFO' database and CAS.

The manuscript management system is completely online and includes a very quick and fair peer-review system, which is all easy to use. Visit http://www.dovepress.com/testimonials.php to read real quotes from published authors.

\footnotetext{
Submit your manuscript here: http://www.dovepress.com/neuropsychiatric-disease-and-treatment-journal
} 